\title{
Ebselen Improves Ischemia-Reperfusion Injury After Rat Lung Transplantation
}

\author{
Jürg Hamacher · Uz Stammberger • \\ Elvira Weber · Rudolf Lucas · Albrecht Wendel
}

Received: 15 July 2008/ Accepted: 6 January 2009/Published online: 7 February 2009

(C) Springer Science+Business Media, LLC 2009

\begin{abstract}
The heterocyclic organic compound ebselen (2phenyl-1,2-benizsoselenazol-3(2H)-one) is a glutathione peroxidase mimick with protective properties against oxidative injury. Ebselen also has anti-inflammatory activity, including attenuation of tumor necrosis factor release and increase of interleukin-10, as shown in vivo, in inflammatory and ischemia-reperfusion injuries, including those of the lung. This study was designed to assess its effect on severe ischemia-reperfusion injury in a model of left-sided rat lung isotransplantation. Orthotopic single left-sided lung allotransplantation (Wistar to Wistar) was performed in female rats after a total ischemic time of $18 \mathrm{~h}$. In nine recipients given $500 \mathrm{mg} / \mathrm{kg}$ oral ebselen $1 \mathrm{~h}$ before transplantation, graft $\mathrm{PaO}_{2} / \mathrm{FiO}_{2}$ was improved $24 \mathrm{~h}$ after transplantation, as evidenced with a mean (standard deviation) $\mathrm{PaO}_{2}$ of 139 (61) $\mathrm{mmHg}$ vs. eight controls with 65 (33) $\mathrm{mmHg}(p=0.009)$. Bronchoalveolar PMN count was
\end{abstract}

This work was supported by the Deutsche Forschungsgemeinschaft (FOR 321/2-1; research group "Endogenous tissue injury:

Mechanisms of autodestruction").

J. Hamacher · E. Weber $\cdot$ R. Lucas · A. Wendel

Biochemical Pharmacology, University of Konstanz,

Konstanz, Germany

J. Hamacher ( $\square)$

Pulmonary Division, University Hospital Inselspital,

CH-3010 Bern, Switzerland

e-mail: hamacher@greenmail.ch

U. Stammberger

Division of General Thoracic Surgery, University Hospital

Inselspital, Bern, Switzerland

R. Lucas

Vascular Biology Center, Medical College of Georgia,

Augusta, GA, USA reduced to approximately 50\% in the ebselen group compared with controls, whereas no difference in the tumor necrosis factor content was found. We conclude that the improvement of lung function in ebselen-treated transplanted rats is mainly the result of the anti-inflammatory activity of the drug during reperfusion.

Keywords Ebselen - Lung transplantation .

Reperfusion injury $\cdot$ Anti-inflammatory agents

\section{Introduction}

Ebselen (2-phenyl-1,2-benzisoselenazol-3(2H)-one) is a selenium-containing organic compound that has protective properties against oxidative injury by mimicking the activity of the selenoenzyme glutathione peroxidase, i.e., by catalyzing the reduction of hydrogen peroxide or lipid hydroperoxides to the corresponding alcohols and water via oxidation of reduced glutathione [1,2]. Furthermore, ebselen inhibitis 5-lipoxygenase, inducible NO synthase, and NADPH-cytochrome P-450 reductase [3-5]. The inactivation of leukotriene $\mathrm{B} 4$ by isomerization to its inactive 6-trans form by ebselen was one of the primary findings to explain the anti-inflammatory activity of ebselen, which was later extended to immunopharmacological in vivo actions, such as protection of endotoxin-challenged mice or protection against T-cell-mediated hepatic injury via attenuation of tumor necrosis factor (TNF)- $\alpha$ and increase of interleukin10 release [6-10]. The observation that in vitro ebselen scavenges peroxynitrite $[11,12]$ needs its clear significance in vivo confirmed $[13,14]$. Animal inflammatory and cerebral, cardiac, hepatic, and renal ischemia-reperfusion or toxic injury models as well as protection from noise exposure demonstrated its anti-inflammatory or organ-preserving 
pharmacological potential [7, 15-29]. In models of alveolar inflammation, edema generation was virtually blocked, and bronchoalveolar lavage TNF- $\alpha$ was dose-dependently reduced [13, 30-32]. In the presence of ebselen, the surfactant peroxidation caused by polymorphonuclear neutrophil granulocytes (PMN) could significantly be reduced, as elegantly shown by in vitro models [33]. In a clinical setting, ebselen could reduce the infarct size of stroke patients. A study showed that patients with acute ischemic stroke and with complete occlusion of the middle cerebral artery had smaller infarct sizes in the ebselentreated group than in usual control treatments [34].

Pulmonary ischemia-reperfusion injury after transplantation leads to a noncardiogenic hyperpermeability pulmonary edema, together with a variable degree of inflammation [35]. Lung transplantation after prolonged graft ischemia may result in severe, highly inflammatory, acute lung injury [36]. A powerful nonspecific immune response occurs in both the interstitial and alveolar space, with polymorphonuclear neutrophils, complement activation, and cytokine release, such as interleukin- 8 or TNF, and radicals are thought to play a central role in its pathogenesis [36-38]. This clinical background prompted us to assess the efficacy of ebselen on severe ischemia-reperfusion injury. We used a model of left-sided rat lung allotransplantation with a prolonged period of total ischemia of $18 \mathrm{~h}$. Outcome parameters were the graft's gas exchange assessed at $24 \mathrm{~h}$ after transplantation, as well as surrogates of the alveolar inflammatory process that occurred in form of a reperfusion injury.

\section{Material and Methods}

Weight-matched female Wistar rats, weighing 226 (standard deviation, 15) g, received orthotopic single left lung allografts after a total graft ischemia of $18 \mathrm{~h}$; nine recipients were treated with $500 \mathrm{mg} / \mathrm{kg}$ oral ebselen $1 \mathrm{~h}$ before reimplantation compared with eight vehicle-only controls. A cuff technique for the vessel anastomoses and a running suture for the bronchial anastomosis were applied. The experiments were performed according to the Helsinki convention for the use and care of animals and were approved by the local review boards for animal care.

\section{Donor Procedure}

Animals were anesthetized by intraperitoneally administered pentobarbital $(50 \mathrm{mg} / \mathrm{kg})$ and heparinized (500 IU/ $\mathrm{kg}$ ). A tracheotomy was performed, and the animals were ventilated through a $14 \mathrm{G}$ catheter (Insyte, Becton Dickinson, Madrid, Spain) by a Unno rodent ventilator (Hugo Sachs Harvard Apparatus, March-Hugstetten, Germany) at a tidal volume of $8 \mathrm{ml} / \mathrm{kg}$ at 100/,, $\mathrm{FiO}_{2}=1.0$. After median sternotomy, division of the inferior vena cava, and resection of the left appendix of the heart, a small silicon tube was inserted into the main pulmonary artery. Both lungs were flushed with $20 \mathrm{ml}$ of low potassium dextrane (LPD) solution (Perfadex ${ }^{\circledR}$, provided by Xvivo, Göteborg, Sweden) at a pressure of $20 \mathrm{~cm} \mathrm{H}_{2} \mathrm{O}$. The trachea was tied in end-inspiration, the heart-lung block removed, the left lung dissected, and $16 \mathrm{G}$ cuffs were placed around its pulmonary artery and vein. The vessels were inverted and tied onto the cuff with an 8-0 monomeric filament. The lung was stored in LPD solution at $1.5^{\circ} \mathrm{C}$ until implantation.

\section{Recipient Procedure}

In the treatment group, $500 \mathrm{mg} / \mathrm{kg}$ of ebselen was given by a feeding tube in $2 \mathrm{ml}$ (consisting of 10\% vehicle solution for cyclosporine A as a dissolvent, provided by Novartis, Basel, Switzerland, and $90 \% \mathrm{NaCl} 0.9 \%$ ), $1 \mathrm{~h}$ before reimplantation, or vehicle, respectively, in the control group.

Transplantation was performed after $18 \mathrm{~h}$ of cold ischemia at $1.5^{\circ} \mathrm{C}$. The recipient was anesthetized by breathing $4 \%$ halothane in a glass chamber followed by endotracheal transoral intubation with a $14 \mathrm{G}$ catheter (Insyte, Becton Dickinson, Madrid, Spain). Anesthesia was maintained with halothane $2 \%$. A left lateral thoracotomy was performed in the fourth intercostal space. The left hilum was dissected. After clamping the left pulmonary artery and vein with removable microvascular clips, the pulmonary vein was opened, flushed with heparinized saline solution, and the cuff was inserted and fixed with 60 silk. With the same technique, the pulmonary artery was anastomosed. The native left lung was removed and the bronchial anastomosis performed with a running over-andover suture with 9-0 Monosof (Tyco Healthcare, Wollerau, Switzerland). The lung was first reventilated and then reperfused. A chest tube was inserted and the thoracotomy closed. The chest tube was removed after restoration of spontaneous breathing when the animal was extubated.

\section{Assessment}

Twenty-four hours after transplantation, the recipient animal was anesthetized by intraperitoneal pentobarbital $(50 \mathrm{mg} / \mathrm{kg})$ and ventilated after tracheotomy with an $\mathrm{FiO}_{2}$ of 1.0 at 100 per min, a tidal volume of $8 \mathrm{ml} / \mathrm{kg}$, and a positive end-expiratory pressure (PEEP) of $5 \mathrm{~cm} \mathrm{H}_{2} \mathrm{O}$, and performing all 2-min recruitment maneuvers through the doubling of tidal volume by blocking the expiratory respiratory circuit most proximal possible to the animal's tube immediately after the $\mathrm{T}$ piece that reunites inspiratory and expiratory tubing and the Luer lock tube connection. For functional assessment of the transplanted left lung, the 
right hilum was dissected and the right pulmonary artery and right main bronchus were occluded with microvascular clips. Five minutes after occlusion, a steady state was reached and an arterial blood gas sample was drawn from the thoracic aorta and assessed (ABL50 blood gas analyzer, Radiometer Copenhagen). After intracardiac heparinization with $500 \mathrm{U} / \mathrm{kg}$, a bronchoalveolar lavage (BAL) was performed in the left lung (as the right main bronchus was clipped) with $2 \mathrm{ml}$ of PBS. The microvascular clips were then removed and the lungs were flushed with $20 \mathrm{ml}$ of saline solution through the pulmonary artery. The heartlung block was excised and the lungs separated: one slice of approximately 4-mm thickness at the height between middle and lower third of the left lung leading to the hilus was put in $10 \%$ PBS-buffered formalin solution (Sigma), paraffin-embedded, of which $4-\mu \mathrm{m}$ slides were colored with hematoxylin-eosin for histology. The remaining left (three portions) and right (three portions) lung tissue was stored at $-70^{\circ} \mathrm{C}$.

BAL cell count was performed with a hemocytometer, and a cytocentrifugation preparation was performed with $100 \mu \mathrm{l}$ of BAL fluid in cytospin inserts (Themo Shandon, Pittsburgh, PA, USA) in a Heraeus Minifuge RF centrifuge ( 8 min, $70 \mathrm{~g}$; Heraeus, Wernheim, Germany), which was stained with May-Grünwald Giemsa to perform a 300-cell differential count. BAL fluid supernatant and serum were obtained after centrifugation $\left(10 \mathrm{~min}, 300 \mathrm{~g}\right.$ at $4^{\circ} \mathrm{C}$, Heraeus Minifuge RF) and stored at $-20^{\circ} \mathrm{C}$ until analysis. The bronchoalveolar supernatant protein content was determined with the method of Pierce et al. according to the manufacturer's protocol.

\section{Statistical Analysis}

For $\mathrm{PaO}_{2}$, the mean (standard deviation), and for histological grading, the median (range) is given. Two-sided tests were used: $t$ tests for continuous variables if normally distributed, and the Mann-Whitney $U$ test for non-Gaussian distributed or categorical variables were applied, respectively. Boxplots were used, indicating median, 25th and 75th percentile as well as 10th and 90th percentile of distribution. The Systat software version 10.2, Systat, Abingdon, USA) was used. $p \leq 0.05$ was considered significant.

\section{Results}

Graft $\mathrm{PaO}_{2} / \mathrm{FiO}_{2}$ at $24 \mathrm{~h}$ after transplantation in nine recipients treated with $500 \mathrm{mg} / \mathrm{kg}$ of oral ebselen $1 \mathrm{~h}$ before reimplantation was superior with a $\mathrm{PaO}_{2}$ of 139 (61) mmHg compared with vehicle-only controls with 65 (33) $\mathrm{mmHg}(p=0.009$; Fig. 1$)$.

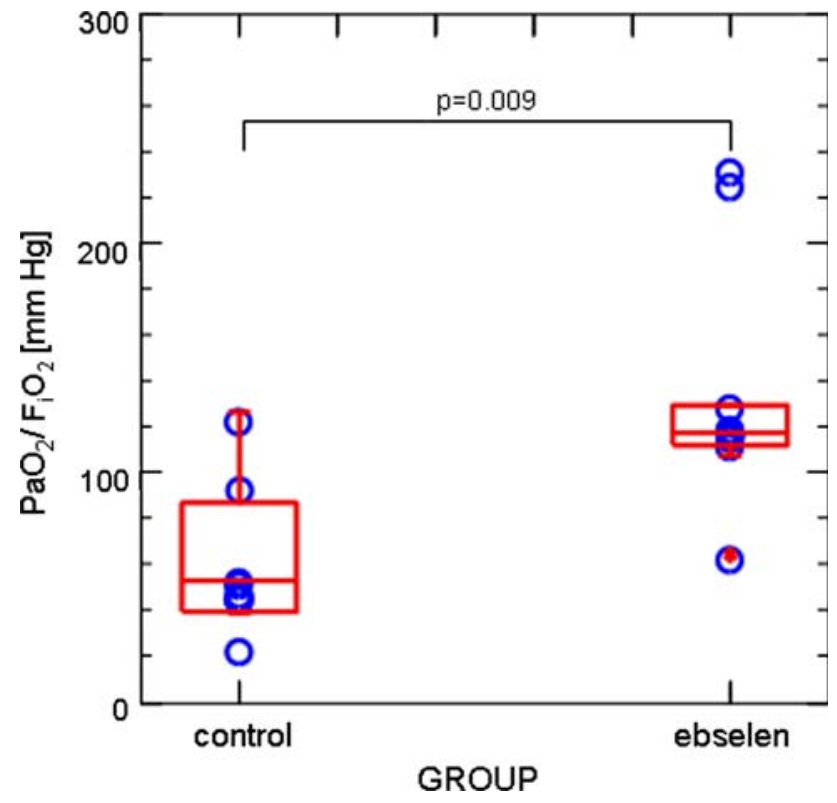

Fig. $1 \mathrm{PaO}_{2} / \mathrm{FiO}_{2}$ of the transplanted left lung determined by blood gas analysis $5 \mathrm{~min}$ after exclusion of the right-sided lung by an arterial and a bronchial clamp. The boxplots indicate median, 25th and 75 th percentile, as well as 10th and 90th percentile of distribution

Bronchoalveolar lavage cell counts and differentials, their significance levels, and cytokine levels are given in Table 1. The absolute PMN count of the ebselen and the vehicle control group is given in Fig. 2.

Histology revealed in both study groups a grossly conserved lung structure, engorged alveolar septa with mainly polymorphonuclear neutrophil leukocyte (PMNs) infiltrates, important alveolar haemorrhage, alveolar proteinaceous material consistent with exudate, and moderate to marked alveolar PMNs. Widened perivascular and peribronchial spaces could be observed, without changes in bronchial or bronchiolar epithelium. Histologically, there was a marked acute neutrophil pleuritis. However, there was no clear evidence of difference in inflammatory changes in the two treatment groups (not shown).

\section{Discussion}

This study demonstrates in a model of severe acute lung injury by ischemia and reperfusion that ebselen pretreatment results in a clearly improved gas exchange of the transplanted lung associated with much less increase of the bronchoalveolar PMN count, whereas the alveolar protein content as a rough measure of the alveolar-capillary barrier function was not significantly decreased. Due to the complexity of the model we refrained from performing further dose-finding studies in view of the obvious results obtained at the single dose chosen. 
Table 1 Bronchoalveolar lavage fluid findings at $24 \mathrm{~h}$ posttransplantation
Values are indicated as mean (SD)

\begin{tabular}{llll}
\hline & Ebselen treatment $(n=9)$ & Vehicle control $(n=8)$ & $p$ \\
\hline $\begin{array}{l}\text { Bronchoalveolar lavage cell count } \\
\text { \% of polymorphonuclear neutrophil } \\
\quad \text { granulocytes (PMN) }\end{array}$ & $34 * 10^{4}\left(10^{*} 10^{4}\right) / \mathrm{ml}$ & $50^{*} 10^{4}\left(13^{*} 10^{4}\right) / \mathrm{ml}$ & 0.09 \\
Absolute PMN count & $20 * 10^{4}\left(7 * 10^{4}\right) / \mathrm{ml}$ & $74(5) \%$ & 0.004 \\
Absolute red blood cell count & $690 * 10^{4}\left(372 * 10^{4}\right) / \mathrm{ml}$ & $767^{*} 10^{4}\left(410^{*} 10^{4}\right) / \mathrm{ml}$ & 0.69 \\
Protein content & $7.5(1) \mathrm{g} / 100 \mathrm{ml}$ & $9.0(1.3) \mathrm{g} / 100 \mathrm{ml}$ & 0.16 \\
TNF & $1(2) \mathrm{pg} / \mathrm{ml}$ & $13(21) \mathrm{pg} / \mathrm{ml}$ & 0.16 \\
CINC-3 & $79(73)$ & $157(241) \mathrm{pg} / \mathrm{ml}$ & 0.38 \\
IL-10 & $22(20)$ & $51(54) \mathrm{pg} / \mathrm{ml}$ & 0.19 \\
\hline
\end{tabular}

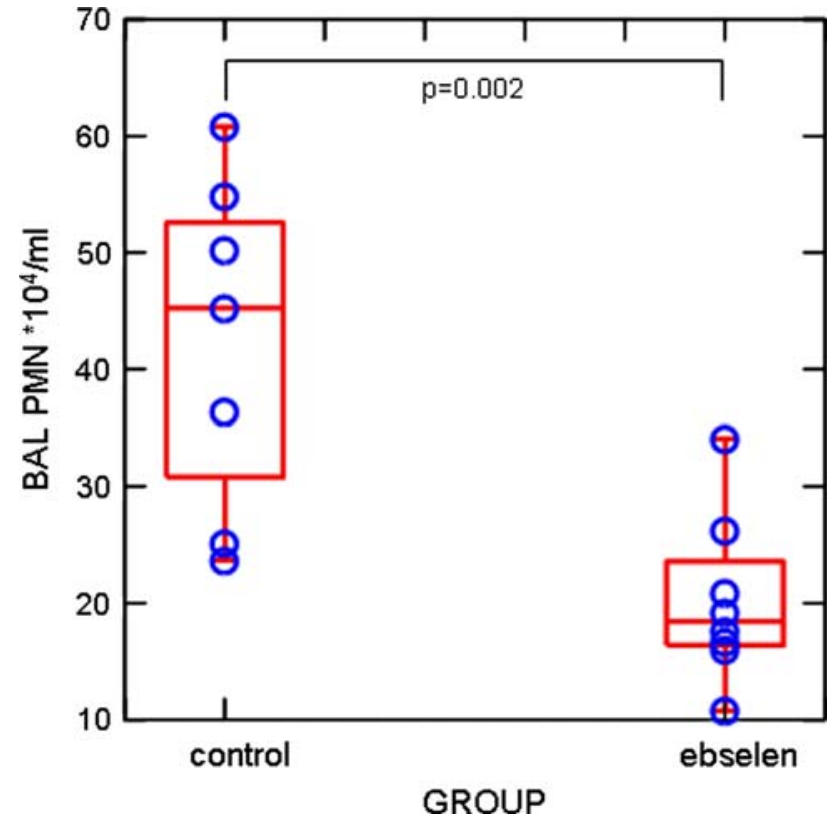

Fig. 2 Polymorphonuclear granulocyte count of transplanted left lung's bronchoalveolar lavage fluid. The boxplots indicate median, 25 th and 75 th percentile, as well as 10th and 90th percentile of distribution

The observed reduction of severe acute lung injury in this clinically oriented in vivo-model is in accordance to several previous findings on experimental lung injury. Intratracheally or intravenously administered Sephadex beads trigger both a nonspecific inflammation and, due to endogenous rat hypersensitivity to dextrane, a hypersensitivity reaction which leads at $24 \mathrm{~h}$ to a highly cellular, i.e., mixed neutrophilic, but also eosinophilic and lymphocytic alveolitis with interstitial lung edema [30, 39]. After ebselen pretreatment, Cotgreave et al. observed in this Sephadex model that the development of lung edema could be completely inhibited [30]. Belvisi et al. demonstrated with a similar injury a dose-related inhibition of lung edema by ebselen with an ED50 of approximately $5 \mathrm{mg} / \mathrm{kg}$ [31]. TNF- $\alpha$ has been shown to be a mediator in animal models of both acute lung injury-induced and antigeninduced lung edema [37, 39, 40, 41]. Although Belvisi et al. observed a reduction of bronchoalveolar lavage supernatant TNF- $\alpha$ by a factor of three at doses of $10 \mathrm{mg} /$ $\mathrm{kg}$ or more, parallel to the pulmonary edema reduction, no significant inhibitory effect was seen concerning bronchoalveolar endothelin-1 [31]. Whereas in the Sephadex model ebselen reduced the lymphocytes and eosinophil count, the neutrophil count remained virtually unchanged in one study [30]. This parameter was not determined in the study of Belvisi et al. who found TNF- $\alpha$ reduced in the BAL [31]. However, a further Sephadex study demonstrated that the administration of the TNF- $\alpha$ blocking soluble TNF type I receptor-IgG heavy chain complex clearly reduced the neutrophil, but not eosinophil BAL count, underlining a critical role of TNF- $\alpha$ in the neutrophilic inflammation of such injury.

In our study, where surgical or microtraumatic stress plus ischemia/reperfusion rather than an artificial inflammatory challenge was used, PMN were reduced in the BAL by a single and early ebselen pretreatment. Because we did not find a significant difference in BAL TNF- $\alpha$ levels between the studied animal groups, we can neither attribute this attenuation of PMN infiltration to known in vitro or in vivo TNF- $\alpha$ effects, nor exclude this possibility [8-10]. One possible explanation might be the late point of TNF- $\alpha$ determination in BAL at $24 \mathrm{~h}$ after reperfusion that we used in that study, which may be much after its peak tissular release [37]. Furthermore, the lack of a significant difference in TNF- $\alpha$ as well as the bronchoalveolar protein levels may be attributed in part to a larger variation in the transplant model: at least in the Sephadex model an attenuation of the capillary leak by such ebselen treatment was observed [31]. Bronchoalveolar protein content has been assessed as a rough measure of the capillary-alveolar function. However, although the increase in bronchoalveolar protein content is a good measure of an increase in capillary-alveolar permeability in the acute phase of lung injury, it may be misleading in a later phase when the healing of the capillary-alveolar barrier coincides with pulmonary edema resolution. Actually, the protein concentration may double in the alveolar fluid in less than $24 \mathrm{~h}$ because fluid reabsorption is much faster than protein 
reabsorption. Because bronchoalveolar lavage artificially reintroduces free fluid in the alveolus, interpretation of alveolar protein content must be done with caution in later points of acute lung injury.

Histological differences were not evident, which is the case in this model even with important functional difference. One reason may be that one usually cannot assess alveolar edema unless fixation is specifically aimed at this, and the other is that small differences can much more reliably be assessed when principles of unbiased stereology are followed [42].

Whether other actions of ebselen, such as that on leukotrienes, or more general signal transduction-modulating effects or radical scavenger effects of ebselen contribute to the improvement seen in our model, remains unanswered $[1,2,6]$. Because reactive-oxygen species are considered important effectors of the hypoxic pulmonary vasoconstriction, the anti-oxidative properties of ebselen might increase blood flow in the worst ventilated areas, therefore, increase ventilation-perfusion mismatch and thus decrease $\mathrm{PaO}_{2} / \mathrm{FiO}_{2}$ in ebselen-treated animals during assessment. However, the magnitude of effect between ebselen-treated and control animals was high, and this difference between groups could only be underestimated by such a postulated, but pathophysiologically described, effect of decreasing hypoxic pulmonary vasoconstriction due to ebselen [43].

\section{Conclusions}

Ebselen significantly improved the transplanted rat lung function at $24 \mathrm{~h}$ after transplantation. The pharmacodynamic potency of ebselen in this model seems comparable with a combined PAF and endothelin inhibition in a similar setting, but less potent than complement blockade [36, 44]. Therefore, the drug may be regarded as an interesting antiinflammatory adjunct to other blocking strategies in pulmonary reperfusion injury.

\section{References}

1. Parnham MJ, Kindt S (1984) A novel biologically active selenoorganic compound-III. Effects of PZ 51 (Ebselen) on glutathione peroxidase and secretory activities of mouse macrophages. Biochem Pharmacol 33:3247-3250. doi:10.1016/0006-2952(84) 90085-6

2. Wendel A, Fausel M, Safayhi H, Tiegs G, Otter R (1984) A novel biologically active seleno-organic compound-II. Activity of PZ 51 in relation to glutathione peroxidase. Biochem Pharmacol 33:3241-3245. doi:10.1016/0006-2952(84)90084-4

3. Hattori R, Inoue R, Sase K, Eizawa H, Kosuga K, Aoyama T, Masayasu H, Kawai C, Sasayama S, Yui Y (1994) Preferential inhibition of inducible nitric oxide synthase by ebselen. Eur $\mathrm{J}$ Pharmacol 267:R1-R2
4. Wendel A, Otter R, Tiegs G (1986) Inhibition by ebselen of microsomal NADPH-cytochrome P450-reductase in vitro but not in vivo. Biochem Pharmacol 35:2995-2997. doi:10.1016/00062952(86)90376-X

5. Cotgreave IA, Duddy SK, Kass GE, Thompson D, Moldeus P (1989) Studies on the anti-inflammatory activity of ebselen. Ebselen interferes with granulocyte oxidative burst by dual inhibition of NADPH oxidase and protein kinase C? Biochem Pharmacol 38:649-656. doi:10.1016/0006-2952(89)90211-6

6. Patrick RA, Peters PA, Issekutz AC (1993) Ebselen is a specific inhibitor of LTB4-mediated migration of human neutrophils. Agents Actions 40:186-190. doi:10.1007/BF01984060

7. Wendel A, Tiegs G (1986) A novel biologically active selenoorganic compound-VI. Protection by ebselen (PZ 51) against galactosamine/endotoxin-induced hepatitis in mice. Biochem Pharmacol 35:2115-2118. doi:10.1016/0006-2952(86)90578-2

8. Wendel A, Kuesters S, Tiegs G (1997) Ebselen: an in vivo immune response modifier. Biomed Environ Sci 10:253-259

9. Tiegs G, Kusters S, Kunstle G, Hentze H, Kiemer AK, Wendel A (1998) Ebselen protects mice against T cell-dependent, TNFmediated apoptotic liver injury. J Pharmacol Exp Ther 287:10981104

10. d'Alessio P, Moutet M, Coudrier E, Darquenne S, Chaudiere J (1998) ICAM-1 and VCAM-1 expression induced by TNF-alpha are inhibited by a glutathione peroxidase mimic. Free Radic Biol Med 24:979-987. doi:10.1016/S0891-5849(97)00396-1

11. Briviba K, Roussyn I, Sharov VS, Sies H (1996) Attenuation of oxidation and nitration reactions of peroxynitrite by selenomethionine, selenocystine and ebselen. Biochem J 319(Pt 1):13-15

12. Daiber A, Zou MH, Bachschmid M, Ullrich V (2000) Ebselen as a peroxynitrite scavenger in vitro and ex vivo. Biochem Pharmacol 59:153-160. doi:10.1016/S0006-2952(99)00309-3

13. Ishii Y, Hashimoto K, Hirano K, Morishima Y, Mochizuki M, Masuyama K, Nomura A, Sakamoto T, Uchida Y, Sagai M, Sekizawa K (2000) Ebselen decreases ozone-induced pulmonary inflammation in rats. Lung 178:225-234

14. Brodsky SV, Gealekman O, Chen J, Zhang F, Togashi N, Crabtree M, Gross SS, Nasjletti A, Goligorsky MS (2004) Prevention and reversal of premature endothelial cell senescence and vasculopathy in obesity-induced diabetes by Ebselen. Circ Res 94:377-384. doi:10.1161/01.RES.0000111802.09964.EF

15. Gao JX, Issekutz AC (1994) The effect of ebselen on T-lymphocyte migration to arthritic joints and dermal inflammatory reactions in the rat. Int J Immunopharmacol 16:279-287. doi: 10.1016/0192-0561(94)90002-7

16. Haraoka M, Matsumoto T, Mizunoe Y, Takahashi K, Kubo S, Koikawa Y, Tanaka M, Sakamoto Y, Sakumoto M, Nagafuji T (1995) Effect of ebselen on renal scarring in rats following renal infection. Chemotherapy 41:208-213

17. Johshita H, Sasaki T, Matsui T, Hanamura T, Masayasu H, Asano T, Takakura K (1990) Effects of ebselen (PZ51) on ischaemic brain oedema after focal ischaemia in cats. Acta Neurochir Suppl (Wien) 51:239-241

18. Kondoh S, Nagasawa S, Kawanishi M, Yamaguchi K, Kajimoto S, Ohta T (1999) Effects of ebselen on cerebral ischemia and reperfusion evaluated by microdialysis. Neurol Res 21:682-686

19. Sui H, Wang W, Wang PH, Liu LS (2005) Protective effect of antioxidant ebselen (PZ51) on the cerebral cortex of stroke-prone spontaneously hypertensive rats. Hypertens Res 28:249-254. doi: 10.1291/hypres.28.249

20. Kalayci M, Coskun O, Cagavi F, Kanter M, Armutcu F, Gul S, Acikgoz B (2005) Neuroprotective effects of ebselen on experimental spinal cord injury in rats. Neurochem Res 30:403-410. doi:10.1007/s11064-005-2615-2

21. Miorelli ST, Rosa RM, Moura DJ, Rocha JC, Lobo LA, Henriques JA, Saffi J (2008) Antioxidant and anti-mutagenic effects of 
ebselen in yeast and in cultured mammalian V79 cells. Mutagenesis 23:93-99. doi:10.1093/mutage/gem048

22. Hoshida S, Kuzuya T, Nishida M, Yamashita N, Hori M, Kamada T, Tada M (1994) Ebselen protects against ischemia-reperfusion injury in a canine model of myocardial infarction. Am J Physiol 267:H2342-H2347

23. Maulik N, Yoshida T (2000) Oxidative stress developed during open heart surgery induces apoptosis: reduction of apoptotic cell death by ebselen, a glutathione peroxidase mimic. J Cardiovasc Pharmacol 36:601-608. doi:10.1097/00005344-200011000-00009

24. Baljinnyam E, Hasebe N, Morihira M, Sumitomo K, Matsusaka T, Fujino T, Fukuzawa J, Ushikubi F, Kikuchi K (2006) Oral pretreatment with ebselen enhances heat shock protein 72 expression and reduces myocardial infarct size. Hypertens Res 29:905-913. doi:10.1291/hypres.29.905

25. Ozaki M, Nakamura M, Teraoka S, Ota K (1997) Ebselen, a novel anti-oxidant compound, protects the rat liver from ischemia-reperfusion injury. Transpl Int 10:96-102

26. Noiri E, Nakao A, Uchida K, Tsukahara H, Ohno M, Fujita T, Brodsky S, Goligorsky MS (2001) Oxidative and nitrosative stress in acute renal ischemia. Am J Physiol Renal Physiol 281:F948-F957

27. Dhanarajan R, Abraham P, Isaac B (2006) Protective effect of ebselen, a selenoorganic drug, against gentamicin-induced renal damage in rats. Basic Clin Pharmacol Toxicol 99:267-272. doi: 10.1111/j.1742-7843.2006.pto_474.x

28. Yamasoba T, Pourbakht A, Sakamoto T, Suzuki M (2005) Ebselen prevents noise-induced excitotoxicity and temporary threshold shift. Neurosci Lett 380:234-238. doi:10.1016/j.neulet. 2005.01.047

29. Kil J, Pierce C, Tran H, Gu R, Lynch ED (2007) Ebselen treatment reduces noise induced hearing loss via the mimicry and induction of glutathione peroxidase. Hear Res 226:44-51. doi: 10.1016/j.heares.2006.08.006

30. Cotgreave IA, Johansson U, Westergren G, Moldeus PW, Brattsand R (1988) The anti-inflammatory activity of Ebselen but not thiols in experimental alveolitis and bronchiolitis. Agents Actions 24:313-319. doi:10.1007/BF02028288

31. Belvisi MG, Haddad EB, Battram C, Birrell M, Foster M, Webber S (2000) Anti-inflammatory properties of ebselen in a model of sephadex-induced lung inflammation. Eur Respir J 15:579-581. doi:10.1034/j.1399-3003.2000.15.25.x

32. Haddad el-B, McCluskie K, Birrell MA, Dabrowski D, Pecoraro M, Underwood S, Chen B, De Sanctis GT, Webber SE, Foster ML, Belvisi MG (2002) Differential effects of ebselen on neutrophil recruitment, chemokine, and inflammatory mediator expression in a rat model of lipopolysaccharide-induced pulmonary inflammation. J Immunol 169:974-982
33. Bouhafs RK, Jarstrand C (2002) Effects of antioxidants on surfactant peroxidation by stimulated human polymorphonuclear leukocytes. Free Radic Res 36:727-734. doi:10.1080/10715760 290032593

34. Ogawa A, Yoshimoto T, Kikuchi H, Sano K, Saito I, Yamaguchi T, Yasuhara H (1999) Ebselen in acute middle cerebral artery occlusion: a placebo-controlled, double-blind clinical trial. Cerebrovasc Dis 9:112-118. doi:10.1159/000015908

35. de Perrot M, Liu M, Waddell TK, Keshavjee S (2003) Ischemiareperfusion-induced lung injury. Am J Respir Crit Care Med 167:490-511. doi:10.1164/rccm.200207-670SO

36. Stammberger U, Hamacher J, Hillinger S, Schmid RA (2000) $\mathrm{sCR} 1 \mathrm{sLeX}$ ameliorates ischemia/reperfusion injury in experimental lung transplantation. J Thorac Cardiovasc Surg 120:10781084. doi: $10.1067 / \mathrm{mtc} .2000 .111175$

37. Sekido N, Mukaida N, Harada A, Nakanishi I, Watanabe Y, Matsushima K (1993) Prevention of lung reperfusion injury in rabbits by a monoclonal antibody against interleukin- 8 . Nature 365:654-657. doi:10.1038/365654a0

38. DeMeester SR, Rolfe MW, Kunkel SL, Swiderski DL, Lincoln PM, Deeb GM, Strieter RM (1993) The bimodal expression of tumor necrosis factor-alpha in association with rat lung reimplantation and allograft rejection. J Immunol 150:2494-2505

39. Jassem W, Roake J (1998) The molecular and cellular basis of reperfusion injury following organ transplantation. Transplant Rev 12:14-33. doi:10.1016/S0955-470X(98)80037-2

40. Gater PR, Wasserman MA, Paciorek PM, Renzetti LM (1996) Inhibition of Sephadex-induced lung injury in the rat by Ro 452081, a tumor necrosis factor receptor fusion protein. Am J Respir Cell Mol Biol 14:454-460

41. Renzetti LM, Paciorek PM, Tannu SA, Rinaldi NC, Tocker JE, Wasserman MA, Gater PR (1996) Pharmacological evidence for tumor necrosis factor as a mediator of allergic inflammation in the airways. J Pharmacol Exp Ther 278:847-853

42. Ochs M (2006) Stereological analysis of acute lung injury. Eur Respir Rev 15:115-121. doi:10.1183/09059180.00010102

43. Waypa GB, Schandel NS, Schumacker PT (2001) Model for hypoxic pulmonary vasoconstriction involving mitochondrial oxygen sensing. Circ Res 88:1259-1266. doi:10.1161/hh1201. 091960

44. Stammberger U, Carboni GL, Hillinger S, Schneiter D, Weder W, Schmid RA (1999) Combined treatment with endothelin- and PAF-antagonists reduces posttransplant lung ischemia/reperfusion injury. J Heart Lung Transplant 18:862-868. doi:10.1016/ S1053-2498(99)00039-X 